problems, well, just send in the nanobots to sort them out. "All technologies," claims Kurzweil, "will essentially become information technologies, including energy.

On the vexed issue of the speed of light, Kurzweil cites evidence that the fine-structure constant, which expresses the strength of the electromagnetic force and contains the speed of light as a factor, may have increased very slightly over the past 6 billion years. The primary evidence comes from an analysis of quasar spectral lines by John Webb of the University of New South Wales in Australia and his collaborators, not from a study of the Oklo natural nuclear reactor in Gabon, as Kurzweil states. Furthermore, even if the observations opened the way to manipulating the value of the fine-structure constant, that is not the same as increasing the speed of light and leaving everything else unchanged. Indeed, the manipulation would involve a reduction of the finestructure constant, which would slow the rate of information processing at the atomic level, and so prove self-defeating.

These technical hiccups are irritating, but the book should not be read as a scientific treatise. Rather, it is a futuristic and somewhat breathless romp across the outer reaches of technological possibility, limited only by human imagination. Kurzweil coins the horrible term 'singularitarian' for someone who embraces his vision with alacrity. If Kurzweil is to be believed, we will all be singularitarians in just 29 years' time. Hang in there.

Paul Davies is at the Australian Centre for Astrobiology, Macquarie University, Sydney, New South Wales 2109, Australia. His latest book is How to Build a Time Machine.

\title{
A taste of a rotten past
}

\section{Sacred Cow, Mad Cow: A History of \\ Food Fears \\ by Madeleine Ferrières \\ Columbia University Press: 2005. 416pp. $\$ 29.50$}

\section{W.F.Bynum}

Among the formidable list of modern anxieties, those related to food safety loom large. Mad cow disease, genetically modified crops, factory farming, residual pesticides, additives - we read about them daily and are reminded of them when we shop by labels assuring us that we don't need to worry when buying this particular product. We are, after all, what we eat; or more to the point, we are defined by what we do not eat.

All these contemporary concerns give Madeleine Ferrières' monograph a powerful topicality. To her credit, she never panders to the worried well, but sticks to a rich and wellexploited range of historical sources: advice manuals, legal records, statutes, court cases, medical textbooks and imaginative literature. Her running theme is boldly stated: food fears are perennial, although they take different forms depending on the cultural milieu. But the subsidiary theme is also amply demonstrated: fear about food quality varies inversely with fear about food quantity, both temporally and through social strata. If your belly is empty, you don't worry too much about additives or saturated fatty acids.

The title of the original French edition highlights the book's chronological coverage, which ranges from the Middle Ages to the beginning of the twentieth century. So there is nothing about mad cow disease here, despite the allusion in the title of the English version. Instead, in earlier generations, domestic animals with tuberculosis, trichinosis, foot-and-mouth disease and a variety of other ailments made their weary way to the butchers, and thence to dinner tables. Many would have been especially weary, having been driven hundreds of miles to urban markets. If they couldn't make it under their own steam, they were not permitted to be sold. Those that could walk the last mile would be inspected, slaughtered and consumed quickly. The idea of allowing meat to age after slaughter is a recent luxury. So is the tendency to eat younger animals, rather than those past their capacity to provide milk or wool.

Ferrières also considers other foodstuffs, notably fruit, vegetables and grain. These invoked their own fears, especially unripe fruit and mouldy bread, but most legislation revolved around meat, which was a central part of diets half-a-millennium ago. Economic circumstance determined whether one ate tripe or rotten meat with one's bread, not whether vegetable stew was the main dish. The poor were often given, or sold cheaply, animals deemed unfit for commercial consumption.

Social fears often generate fantasies of a golden age, when football hooliganism was unknown, crime was low, nudear families feasted on wholesome food, and everyone got on well with their neighbours. There is none of that in this volume: the poor struggled, ate badly and died young. Ferrières argues convincingly, I think, that the nineteenth century created the modern food dilemma. Canning, transportation and, eventually, refrigeration extended the food chain. People who would traditionally have seen, touched and smelled the food they were buying now needed only to read the labels. Instead of trusting themselves, they had to trust others. Food inspection declined as political and economic liberalism grew. At the same time, more widespread affluence put a premium on taste, often at the expense of safety. Miasmatic theories of disease and bourgeois sensibilities ensured that the slaughtering was done outside the city centres. Animals no longer had to be able to walk to their destinies.

Ferrières concentrates primarily on France, although there are insights into other cultural experiences, including the persisting British policy of stamping out disease using wholesale slaughter, which is a clumsy tool of disease control. She has a fine sense of the dramatic, faithfully conveyed in the translation, which is sometimes literal at the expense of easy fluency. Away from France, some of the details become fuzzy: a London suburb appears as Issington, rather than Islington, and George Barker has transmuted into someone called Thomas Halwek.

This book is not for the squeamish, but those interested in the culture of the table, or the historical intersections of health, taste and diet, will find plenty here to satisfy their appetites. W. F. Bynum is at the Wellcome Trust Centre for the History of Medicine, University College London, London NW1 2BE, UK. 